\title{
Vasculite urticariforme hipocomplementêmica como primeira manifestação do lúpus eritematoso sistêmico
}

\author{
I.A. Pereira, R.M.R. Perreira, E.F. Borba, C.R. Gonçalves, N.Y. Yoshinari, W. Cossermelli \\ Disciplina de Reumatologia do Hospital das Clínicas da Faculdade de Medicina da Universidade de São Paulo, São Paulo, SP.
}

\begin{abstract}
RESUMO - A síndrome vasculite urticariforme hipocomplementêmica é uma vasculite leucocitoclástica que se apresenta com lesões urticariformes, associada a febre, artralgias, artrite e cólica abdominal. Outras manifestações sistêmicas incluem a presença de glomerulonefrite, uveíte, episclerite, doença pulmonar obstrutiva e alterações neurológicas. Alguns casos associados ao lúpus eritematoso si stêmico (LES) têm sido descritos, com o diagnóstico baseando-se na presença de critérios bem definidos de LES prévia ou con-
\end{abstract}

\section{INTRODUÇÃO}

A síndrome vasculite urticariforme hipocomplementêmica é um tipo de vasculite incomum, mediada por imunecomplexos, caracterizada pelo aparecimento de lesões urticariformes dolorosas de duração prolongada, acompanhadas de febre, artralgias e cólica abdominal ${ }^{1,4}$.

A relação com o lúpus eritematoso sistêmico (LES) é complexa, já que alguns pacientes apresentam FAN positivo, imunecomplexos circulantes, artrite e glomerulonefrite, o que torna difícil a separação em duas doenças distintas quando associados a hipocomplementemia ${ }^{1,4,5}$. A presença de um anticorpo I gG com capaci dade de preci pitação de Clq tem sido encontrada nos pacientes com síndrome vasculite urticariforme, porém não serve como marcador diagnóstico para diferenciar do LES, já que estes anticorpos também têm sido encontrados nestes pacientes ${ }^{1,4-6}$.

A associ ação de LES com vasculite urticariforme hi pocomplementêmica tem si do bem relatada, sendo caracterizada pela presença de critérios que permitem o diagnóstico do primeiro, inicial mente ${ }^{7}$. A síndrome vasculite urticariforme hipocomplementêmica como manifestação inicial de LES érara, sendo encontrado dois relatos de caso na literatura ${ }^{8,9}$. Relatamos a experiência de dois outros casos de LES que se apresentaram inicialmente como vasculite urticariforme.

Caso 1 - Paciente feminina, 26 anos, internada comitantemente ao aparecimento da vasculite urticariforme. A apresentação de vasculite urticariforme precedendo o diagnóstico de LES é rara, o que motivou o relato destes dois casos. E nfatizase a positivação do anticorpo anti-Ro/ss-A por ocasião do diagnóstico de LES, alertando para a necessidade de avaliação periódica nos casos de vasculite urticariforme.

UNITERMOS: Vasculite urticariforme. Hipocomplementemia. Lúpus eritematoso sistêmico.

no Hospital das Clínicas da F aculdade de Medicina da Universidade de São Paulo (USP) em março de 1988, com história de lesões eritemato-pruriginosas e dolorosas em placas de início há dois anos, com duração de 2 a 3 dias, sendo acompanhadas de poliartralgias, febre e episódios de dor abdominal tipo cólica. Ao exame físico se apresentava febril $\left(39^{\circ} \mathrm{C}\right)$, com lesões urticariformes disseminadas, dor abdominal difusa à palpação e episclerite à avaliação oftal mológica. Os exames laboratoriais mostravam hemoglobina $=8,8 \mathrm{~g} / \mathrm{L}$; hematócrito $=$ $28 \%$; leucóci tos de $4.200 / \mathrm{mm}^{3}$, com $48 \%$ de segmentados, $14 \%$ de bastonetes, $36 \%$ de linfócitos; plaquetas $=520.000 / \mathrm{mm}^{3}$; reticulócitos $=2 \%$; haptoglobina $=369 \mathrm{~g} / \mathrm{L}(\mathrm{nl}$ de $120-400 \mathrm{~g} / \mathrm{L})$; Coombs direto/ indireto negativos; FAN positivo (1/200); cél. LE negativo; anti-DNA, anti-ENA, anti-Ro/SS-A, anti-La/ SS-B negativos; C $3=53 \mathrm{mg} / \mathrm{dL}$ ( $\mathrm{nl}$ de $55-120 \mathrm{mg} / \mathrm{dL}$ ); $\mathrm{CH} 50=162 \mathrm{mg} / \mathrm{dL} ; \mathrm{VHS}=53 \mathrm{~mm} / 1$ a hora; mucoproteínas $=13 \mathrm{mg} / \mathrm{dL}$; fator reumatóide negativo; crioglobulinas negativo; imunecomplexos circulantes $>400 \mathrm{mcg} / \mathrm{mL}(\mathrm{nl}$ até $35 \mathrm{mcg} / \mathrm{mL}$ ); uréia, creatinina e urina I normais. A biópsia de lesão urticariforme mostrou-se compatível com vasculite leucocitoclástica, sendo diagnosticada síndrome vasculite hipocomplementêmica. Evoluiu sem resposta a várias terapêuticas que incluíram antihistamínicos (hidroxizina), cimetidina, indometacina, colchicina e azatioprina. Após 11 meses, passou a apresentar artrite de interfalangianas proximais, hematúria, proteinúria, cilindrúria e positivação do anticorpo anti-Ro/SS-A e células LE. 
Realizada biópsia renal compatível com glomeruIonefrite proliferativa focal e diagnosticado LES. Iniciada pulsoterapia com metilprednisol ona $1 \mathrm{~g} / \mathrm{d} /$ 3 dias e pulsoterapia mensal com ciclofosfamida, tendo sido suspensa por manifestações gastrointestinais importantes. Atualmente em uso de prednisona e cl orambucil, com boa evol ução renal e persistência de al gumas lesões urticariformes.

Caso 2 - Paci ente feminina, 43 anos, internada em outubro de 1987 no Hospital das Clínicas da Faculdade de Medicina da USP com urticária em tronco, membros superiores e inferiores de início há 5 anos, pruriginosas e dolorosas em queimação, acompanhadas de febre e poliartralgias. O exame físico era normal, com exceção das lesões urticariformes. A investigação laboratorial mostrava FAN, células LE, fator reumatóide, crioglobulinas, antiRo/SS-A e anti-La/SS-B negativos; diminuição de C3, C4 e CH50 e a biópsia da lesão revelou vasculite leucocitoclástica. A pesar de discreto rash malar, o diagnóstico de síndrome vasculite hipocomplementêmica foi estabelecido, já que não existiam outras manifestações clíni co-laboratoriais que permitissem o diagnóstico de LES.

Evoluiu sem resposta ao uso de prednisona $20 \mathrm{mg} / \mathrm{d}$ e azatioprina $150 \mathrm{mg} / \mathrm{d}$, sendo reinternada após três meses com quadro de sinovi te de interfalangianas, vasculite de mãos e rash malar. $\mathrm{Na}$ ocasião houve positivação do anti-Ro/SS-A, FAN (padrão pontilhado $>1 / 200$ ) e de células LE. Feito diagnóstico de lúpus eritematoso sistêmico, atualmente vem fazendo uso de prednisona e hidroxizina com controle das manifestações.

\section{DISCUSSÃO}

A partir de 1971, com os relatos de Agnello, seguidos por McDuffie, em 1973, tem-se conhecimento de inúmeros casos de vasculite urticariforme, os quais eram chamados de síndrome relacionada ao LES pela presença de algumas manifestações clínicas e sorológicas em comum²,3,10.

Em 1980, Zeiss et al. melhor caracterizaram esses pacientes do ponto de vista clínico e sorológi co, designando vasculite hipocomplementêmica ${ }^{4}$. Os aspectos clíni cos consistem de urticária crônica, em que as lesões se diferenciam da urticária comum por terem uma maior duração (48-72 horas) e serem dolorosas, em queimação, podendo deixar lesões residuais como púrpura ou hiperpigmentação $0^{1,2-4,11,12}$. A histologia das lesões mostra a presença de vasculite leucocitoclástica ${ }^{11}$. Outras manifestações podem ocorrer e incluem febre, artralgias, artrite, dor abdominal, glomerulonefrite, doença pulmonar obstrutiva, convulsões, meningite asséptica e mononeurite ${ }^{4,5}$. Observa-se uma diminuição acentuada dos níveis séri cos de $c 1 q$, com menor grau de diminuição de clr e cls, redução de c2, c3 e c4 com preservação das úl timas frações do complemento e da via alternativa ${ }^{4}$. A presença de clq precipitinas de baixo peso molecular que se ligam à porção $\mathrm{Fc}$ do $\mathrm{C}$ lq são responsáveis por estas alterações ${ }^{1,4}$. Estas IgG clq precipitinas também têm sido encontradas em pacientes com LES sem vasculite urticariforme, tornando, assim, essas entidades amplamente relacionadas ${ }^{6}$.

A evolução de pacientes com síndrome vasculite urticariforme hipocomplementêmica em LES foi relatada em apenas dois casos na literatura, o que faz com que essas manifestações clínicas devam ser reconheci das como formas de apresentação inicial de LES, como nestes dois casos relatados ${ }^{8,9}$. Alertamos a positivação do anticorpo anti-Ro/SS-A por ocasi ão do diagnóstico de LES e enfatizamos a necessidade de reavaliação periódica nos casos de vasculite urticariforme.

\section{SUMMARY}

\section{Hypocomplementaemic urticarial vasculitis as first manifestation of systemic lupus erythema- tosus}

Hypocomplementaemic urticarial vasculitis syndrome is a leukocytoclastic vasculitis characterized by urticarial lesions, associated with fever, arthralgias, arthritis and abdominal pain. Other systemic manifestations include gl omerulonephritis, uveitis, episcleritis, chronic obstructive pulmonary disease and neurological abnormalities. Some cases associated with systemi c lupus erythematosus have been described and SLE diagnosis was made by previous or concomitant diagnostic criteria before onset of urticarial vasculitis. Urticarial vasculitis prior to SLE diagnosis is rare. The development of anti-Ro/ SS-A antibody for the diagnosis of SLE is emphasized. The authors alert to the importance of periodically searching for this marker in patients with urticarial vasculitis. [Rev Ass Brasil 1997; 43(4): 311-3.]

KEY WORDS: Urticarial vasculitis. Hypocomplementaemia. Systemic lupus erythematosus.

\section{REFERÊNCIAS BIBLIOGRÁFICAS}

1. Agnello V. Complement deficiency states. Medicine (Baltimore) 1978; 57: 1-23.

2. Marder RJ, Rent R, Choi EYC, Gewurz H. Clq deficiency associated with urticarial-like lesions and cutaneous vascu- 
litis. Am J Med 1976; 61: 560-5.

3. McDuffie FC, Sams J r. WM, Maldonado J E et al. Hypocomplementaemia with cutaneous vasculitis and arthritis. Mayo Clin Proc 1973; 48: 340-8.

4. Zeiss CR, Burch FX, Marder RJ et al. A hypocomplementemic vasculitic urticarial syndrome - report of four new cases and definition of the disease. Am J Med 1980; 68: 867-73.

5. Sanchez NP, Winkelmann RK, Schroeter AL, Dicken $\mathrm{CH}$. The clinical and histopathologic spectrums of urticarial vasculitis: study of forty cases. J Am Acad Dermatol 1982; 7: 599-605.

6. Antes U, Heinz HP, Loos M. Evidence for the presence of autoantibodies to the collagen-like portion of $\mathrm{Clq}$ in systemic lupus erythematosus. Arthritis Rheum 1988; 31: 457-64.

7. Asherson RA, D'Cruz D, Stephens CJ M, Mckee PH, Hughes GRV. Urticarial vasculitis in a connective disease clinic: patterns, presentations, and treatment. Semin Arthritis Rheum 1991; 20: 285-96.

8. Bisaccia E, Adamo V, Rozan SW. Urticarial vasculitis progressing to systemic lupus erythematosus. Arch Dermatol 1988; 124: 1.088-90.

9. Coca A, F ont J , Herrero C, Gonzalez MA, Ingelmo M. Hypocomplementaemic vasculitis and systemic lupus erythematosus (letter). J Rheumatol 1987; 14: 854-5.

10. Agnello V, Ruddy S, Winchester RJ , Christian CL, Kunkel HG. Hereditary C2 deficiency in systemic lupus erythematosus and acquired complement abnormalities in an unusual SLE-related syndrome. Birth Defects 1975; 11: 312-7.

11. Berg RE, Kantor GR, Bergfed WF. Urticarial vasculitis in adults. J Am Acad Dermatol 1988; 27: 504-5.

12. Monroe EW. Urticarial vasculitis: an updated review. J Am Acad Dermatol 1981; 5: 88-92. 